\title{
Peramalan Nilai Tukar Rupiah Terhadap Mata Uang Negara Asia Menggunakan Metode Quantum Neural Network
}

\author{
Putu Risanti Iswardani ${ }^{1}$, Made Sudarma ${ }^{2}$, Lie Jasa ${ }^{3}$ \\ [Submission: 16-03-21, Accepted: 08-04-2021]
}

\begin{abstract}
Currency is a standardized payment instrument used all around the world. Almost each country has their own currency, and it has a variable value. Asia is one of the biggest continent in the world. Most tourists whom visit Indonesia come from Asia. Thus, that makes the most currency exchanged in Indonesia are currencies from Asia. Currency exchange rate difference between one currency and another affected by several factor. One of those factor is inflation in its country. To overcome that issue, one needs a prediction system that can be used to predict the exchange rate of currencies in the future. Quantum Neural Network is used in this research to predict Indonesian Rupiah exchange rate value to other currency in Asia. Singapore, Hongkong and Japanese currencies are particularly used in this research. Results obtained from this research are accuracies. Quantum Neural Network produces 99.78\% accuracy on Singapore Dollar to Indonesian Rupiah exchange rate, $99.57 \%$ on Hongkong Dollar to Indonesian Rupiah, and $99.60 \%$ on Japaneseese Yen to Indonesian Rupiah.
\end{abstract}

\section{Keyword - Mata Uang, Nilai Tukar, Prediksi, Quantum Neural} Network.

Intisari- Mata uang merupakan sebuah alat pembayaran yang digunakan di seluruh dunia. Setiap mata uang memiliki nilai yang bervariasi pada setiap negara, sehingga negara yang satu memiliki nilai mata uang yang berbeda dengan negara lainnya. Asia merupakan sebuah benua terbesar dan terluas di dunia. Sebagian besar wisatawan yang mengunjungi Indonesia berasal dari Asia. Sehingga pertukaran mata uang terbanyak yaitu mata uang dari negara-negara yang ada di Asia. Mata uang digunakan sebagai alat tukar antar negara yang bernilai disebut nilai tukar. Perbedaan nilai tukar antara satu negara dengan negara lainnya dipengaruhi oleh beberapa faktor. Salah satu faktor yang mempengaruhi perbedaan nilai tukar yaitu faktor inflasi yang ada di setiap negara. Untuk mengatasi hal tersebut, perlu adanya sebuah permalan nilai tukar yang dapat digunakan untuk memprediksi nilai tukar dimasa mendatang. Quantum Neural Network pada penelitian ini digunakan untuk memprediksi nilai tukar Indonesia dengan beberapa negara di Asia. Mata uang yang digunakan pada penelitian ini yaitu Singapore Dollar, Hongkong Dollar dan Japanese Yen. Hasil yang didapatkan pada penelitian ini yaitu nilai akurasi pada Prediksi Nilai Mata Uang dengan menggunakan Quantum Neural Network sebesar 99.78\% pada Singapore Dollar ke Indonesia Rupiah, $\mathbf{9 9 . 5 7 \%}$ pada Hongkong Dollar ke Indonesia

\footnotetext{
'Mahasiswa, Program Pasca Sarjana, Manajemen Sistem Informasi dan Komputer Fakultas Teknik Universitas Udayana, Jln. P.B. Sudirman, Denpasar, Bali 80232 INDONESIA (tlp: 0361-239599; e-mail: riskawai@gmail.com)

${ }^{2,3}$ Dosen, Program Pasca Sarjana, Magister Teknik Elektro Fakultas Teknik Universitas Udayana, Jln. P.B. Sudirman, Denpasar, Bali 80232

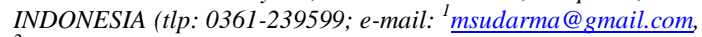
2lieiasa@unud.ac.id
}

Putu Risanti Iswardani : Peramalan Nilai Tukar Rupiah...
Rupiah, dan $\mathbf{9 9 . 6 0 \%}$ pada Japanese Yen ke Indonesian Rupiah.

Kata Kunci- Mata Uang, Nilai Tukar, Prediksi, Quantum Neural Network.

\section{PENDAHULUAN}

Mata uang merupakan alat pembayaran untuk berbagai transaksi ekonomi yang digunakan pada suatu negara. Setiap mata uang memiliki nilai yang bervariasi pada setiap negara, sehingga negara yang satu memiliki nilai mata uang yang berbeda dengan negara lainnya. Selain dijadikan sebagai alat pembayaran transaksi, mata uang juga dapat dijadikan simbol pada setiap negara. Asia merupakan sebuah benua terbesar dan terluas di dunia. Sebagian besar wisatawan yang mengunjungi Indonesia berasal dari Asia. Sehingga pertukaran mata uang terbanyak yaitu mata uang dari negaranegara yang ada di Asia.

Mata Uang Asia terdiri dari 50 negara yang berada di kawasan Asia. Pertukaran mata uang yang berasal dari Asia termasuk pertukaran mata uang asing yang terbanyak yang ada di beberapa moneychanger yang ada di Indonesia. Sehingga erat kaitannya antara Indonesia dengan beberapa negara Asia lainnya. Berdasarkan sumber data yang didapatkan, jumlah transaksi nilai tukar tertinggi yaitu Singapura, Hongkong dan Jepang. Sehingga mata uang yang digunakan pada penelitian ini yaitu nilai tukar Singapore Dollar, Hongkong Dollar dan Japanese Yen terhadap Indonesian Rupiah.

Mata uang digunakan sebagai alat tukar antar negara yang bernilai disebut nilai tukar. Nilai tukar merupakan sebuah nilai dari mata uang yang dilakukan sebagai pembayaran saat ini atau di kemudian hari. Nilai tukar juga berarti penghubung antara dua mata uang masing-masing negara. Setiap negara memiliki besaran jumlah unit yang disebut mata uang. Perbedaan nilai tukar antara satu negara dengan negara lainnya dipengaruhi oleh beberapa faktor. Salah satu faktor yang mempengaruhi perbedaan nilai tukar yaitu faktor inflasi yang ada di setiap negara.

Karena faktor inflasi yang menyebabkan tidak konsistennya Nilai Tukar Rupiah terhadap mata uang negara lainnya. Sehingga masyarakat tidak dapat memperkirakan kapan waktu yang terbaik untuk menukarkan rupiah yang dimilikinya dengan nilai tukar yang tinggi. Maka dari itu, perlu adanya sebuah prediksi yang dapat memperkirakan waktu yang tepat untuk penukaran rupiah terhadap mata uang negara lainnya.

Berdasarkan penelitian [1] penulis menemukan bahwa prediksi nilai tukar dapat digunakan untuk mencapai kesuksesan dalam bidang investasi dan bisnis, sehingga perlu

$$
\text { p-ISSN:1693 - 2951; e-ISSN: 2503-2372 }
$$


diadakan prediksi nilai tukar agar perkiraan keuangan di dalam sebuah bisnis dan investasi dapat diperkirakan secara akurat.

Berdasarkan masalah yang didapatkan maka untuk mengetahui waktu yang terbaik pertukaran mata uang dengan nilai tukar yang tinggi, perlu adanya sebuah prediksi nilai tukar agar mempermudah masyarakat untuk menentukan waktu terbaik untuk menukar uang yang dimilikinya.

Pada jurnal [1], mengusulkan metode Hidden Markov Model untuk memprdiksi nilai tukar Rupiah terhadap Dollar Amerika. Penelitian tersebut melakukan pengujian Mean Absolute Presentage Error (MAPE) dengan hasil presentasi sebesar $4.13 \%$. Dengan menggunakan Quantum Neural Network, diharapkan dapat melakukan prediksi yang lebih baik dibandingkan dengan penelitian sebelumnya dengan harapan hasil pengujian dengan MAPE diatas $90 \%$.

\section{KAJIAN PUSTAKA}

\section{A. Peramalan}

Peramalan merupakan sebuah ilmu yang digunakan untuk memperkirakan suatu kejadian tertentu yang akan terjadi di masa yang akan datang. Peramalan dilakukan dengan mengambil data sample histori data sebelumnya dan menghitung dengan menggunakan kalkulasi untuk memprediksi sebuah kejadian tertentu. Peramalan bisa disebut juga sebagai pengambilan keputusan, karena untuk membuat sebuah peramalan maka seseorang atau peneliti harus mengambil keputusan dari hasil peramalan tersebut. Keputusan yang baik merupakan sebuah keputusan yang dilakukan dengan berbagai pertimbangan, sehingga untuk mendapatkan hasil peramalan yang akurat perlu adanya beberapa pertimbangan yang didasarkan oleh metode-metode tertentu. [3].

\section{B. Nilai Tukar}

Nilai tukar merupakan sebuah nilai dari mata uang yang dilakukan sebagai pembayaran saat ini atau di kemudian hari. Nilai tukar juga berarti penghubung antara dua mata uang masing-masing negara. Setiap negara memiliki besaran jumlah unit yang disebut mata uang. Mata uang digunakan sebagai alat tukar antar negara yang bernilai disebut nilai tukar.

Sistem nilai tukar merupakan niai tukar yang diizinkan untuk memiliki nilai yang berbeda-beda. Nilai yang dimiliki masing-masing negara ditentukan berdasarkan kekuatan pasar atas permintaan dan penawaran nilai tukar mata uang akan cenderung berubah hampir setiam menit maupun detik.

\section{Quantum Neural Network}

Quantum Neural Network (QNN) didasarkan pada ilmu otak dan ilmu kognitif. QNN membangun komputer kuantum melalui teori koneksi Classical Neural Network (CNN), mempelajari masalah dalam komputasi kuantum melalui model CNN. Beberapa masalah dalam komputasi kuantum dipelajari oleh model CNN. QNN yang didasarkan pada komputasi kuantum dan aparatus kuantum meningkatkan struktur dan kinerja CNN dengan memanfaatkan sepenuhnya karakteristik komputasi kuantum, seperti hypervelocity, hyperparallel dan kapasitas eksponensial. QNN sebagai algoritma optimisasi cerdas hybrid yang merupakan realisasi dalam komputer tradisional, disebut sebagai perbaikan pada struktur dan kinerja CNN dengan memperkenalkan gagasan teori kuantum. [21]

Menurut Hou Xuan [21], QNN berbeda dengan CNN, QNN merupakan metode perbaikan dari CNN yang memiliki beberapa keunggalan yaitu:

1. Kapasitas memori eksponensial

2. Skala jaringan kecil dan topologi jaringan sederhana

3. Stabilitas dan validitas yang baik.

4. Kapasitas belajar cepat, pemrosesan informasi berkecepatan tinggi.

5. Potensi untuk menghilangkan amnesia katastropik

QNN merupakan sebuah algoritma berbasis jaringan syaraf. Algoritma quantum didasari oleh komputasi quantum dengan mengadopsi sifat-sifat yang melekat pada jaringan syaraf. Algoritma quantum dikembangkan untuk meningkatkan efisiensi komputasi jaringan syaraf karena pada algoritma ini digunakan untuk mengembangan karakteristik komputasi baru dari jaringan syaraf. Hal yang menjadi dasar dari algoritma quantum yaitu model neuron qubit, dimana neuron qubit menjadi penghubung antara keadaan quantum dengan transisi antar neuron.

\section{Model Dasar Quantum Neuron}

Model dasar neuron kuantum adalah turunan dari neuron model klasik dan dirangkum dalam Gambar 1. Dalam neuron kuantum, semua input dan output berada pada keadaan kuantum. [21]

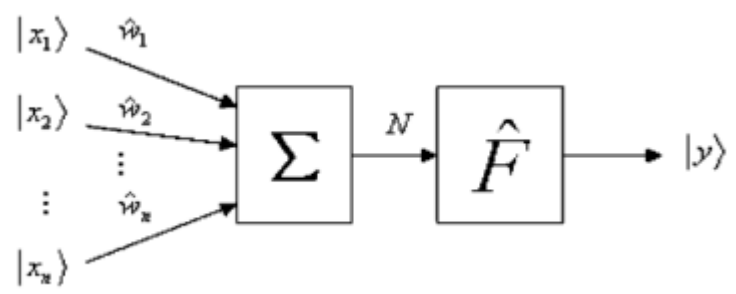

Gambar 1. Model Dasar Quantum Neuron

Model dasar quantum neuron terdiri dari input yang berupa quantum neuron bernilai satu qubit dan output yang berupa hasil dari proses yang dilakukan oleh input. Persamaan (1) merupakan rumus yang digunakan pada proses input.

$$
\begin{aligned}
\mid x_{i} & =\alpha_{i}\left|0+\beta_{i}\right| 1 \\
& ==\left[\begin{array}{ll}
10 & \mid 1
\end{array}\right]\left[\begin{array}{ll}
\alpha_{i} & \beta_{i}
\end{array}\right]^{T}, i=1,2, \ldots, n \ldots \ldots .(1) \\
\mid y & =\hat{F} N \\
& =\hat{F}\left(\widehat{w_{1}}\left|x_{1}+\widehat{w_{2}}\right| x_{2}+\cdots+\widehat{w_{n}} \mid x_{n}\right) \\
& =\hat{F} \sum_{i=1}^{n} \widehat{w_{1}} x_{1}, i=1,2, \ldots, n \quad \ldots \ldots . .(2)
\end{aligned}
$$

Persamaan (2) merupakan rumus dari proses output sebelum didapatkan hasil dari seluruh rangkaian proses. Matriks bobot W1 merupakan sebuah matriks dengan berbasis vektor. F merupakan sebuah operator yang dapat direalisasikan dengan quantum gate network. [21]

\section{E. Mean Absolute Precentage Error (MAPE)}

Statistik pengukuran kesalahan merupakan sebuah peranan penting dalam melacak akurasi peramalan, memantau 
Majalah Ilmiah Teknologi Elektro, Vol. 20, No.1, Januari-Juni 2021

DOI: https://doi.org/10.24843/MITE.2021.v20i01.P18

pengecualian, dan membuat tolak ukur proses perkiraan. Penafsiran statistik ini dapat dikatakan rumit, terutama ketika bekerja dengan data volume rendah atau ketika mencoba menilai akurasi di beberapa item (mis., SKU, lokasi, pelanggan, dll.), sehingga di dalam sebuah peramalan perlu adanya metode akurasi untuk mencocokkan seberapa tinggi tingkat akurasi dari hasil peramalan yang dihasilkan. Penelitian ini menggunakan teknik penghitungan akurasi peramalan yaitu, Mean absolute precentage error (MAPE).

MAPE adalah ukuran statistik seberapa akurat sistem peramalan. MAPE mengukur akurasi sebagai persentase, dan dapat dihitung sebagai kesalahan persentase absolute rata-rata untuk setiap periode waktu dikurangi nilai aktual dibagi dengan nilai aktual. Berikut ini merupakan rumus yang digunakan untuk menghitung akurasi dengan menggunakan MAPE, di mana At adalah nilai aktual dan $\mathrm{Ft}$ adalah nilai perkiraan:

$$
M=\frac{1}{n} \sum_{t=1}^{n}\left|\frac{A t-F t}{A t}\right|
$$

Rasio persentase absolut rata-rata (MAPE) merupakan ukuran paling umum yang digunakan untuk meramalkan kesalahan, dan memiliki kinerja paling baik jika tidak ada ekstrem pada data (dan tidak ada nol).

\section{Metodologi Penelitian}

Penelitian ini melalui 6 tahapan sehingga mencapai tujuan yang akan dicapai. Rincian alur dari penelitian dijabarkan sebagai berikut :

\section{Identifikasi Masalah}

Penelitian tidak dapat dilakukan jika tidak ditemukan sebuah masalah. Masalah di dalam penelitian diidentifikasi terlebih dahulu sebelum ditemukan solusi dari permasalahan yang ada. Tahap pertama dari penelitian ini yaitu mengidentifikasi masalah yang ditemukan pada latar belakang. Masalah yang telah didapat kemudian diidentifikasi sehingga hasil identifikasi tersebut dapat diteliti lebih lanjut untuk mendapatkan jawaban dari masalah yang telah ditemukan.

2. Studi Literatur

Setelah melakukan identifikasi masalah, tahap kedua yang dilakukan penulis yaitu studi literatur. Studi literatur digunakan penulis untuk mengambil data-data dari penelitian sebelumnya. Data yang didapatkan dari studi literatur yaitu metode terkait yang digunakan sebagai data acuan pada penelitian ini

Putu Risanti Iswardani : Peramalan Nilai Tukar Rupiah...

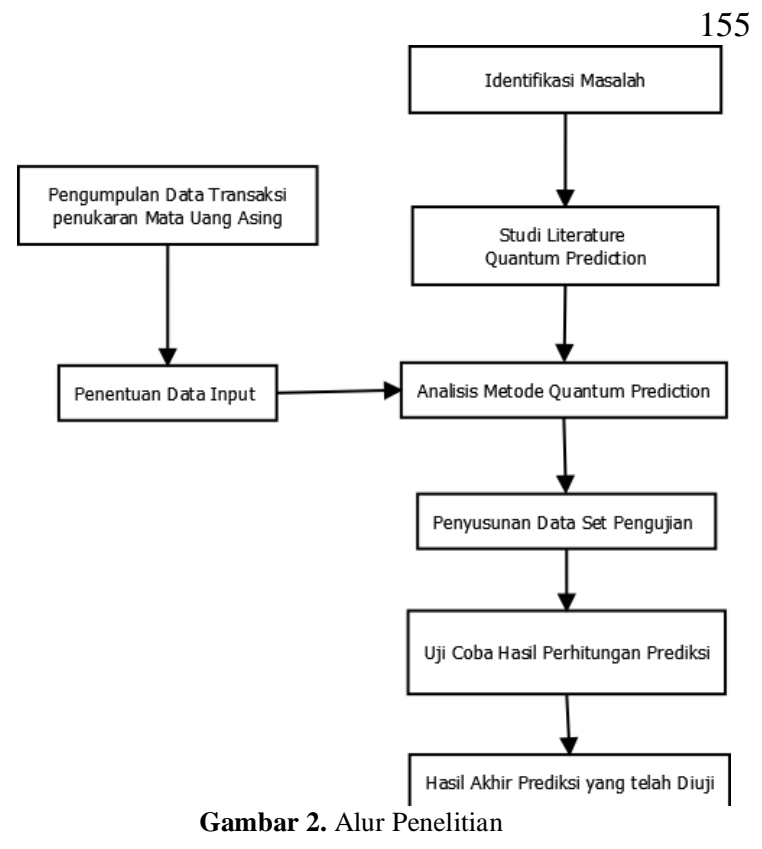

3. Pengumpulan Data Transaksi

Pengumpulan data transaksi pada penelitian ini dilakukan untuk mengumpulkan seluruh data yang akan digunakan sebagai bahan uji. Data yang dikumpulkan yaitu berupa data transaksi nilai tukar Indonesian Rupiah ke Indonesian Rupiah, data nilai tukar Indonesian Rupiah ke Hongkong Dollar, data nilai tukar Indonesian Rupiah ke Japanese Yen di instansi perbankan di Indonesia. Data yang di dapatkan pada sumber data primer akan dibagi menjadi dua, data pertama digunakan sebagai data input dan data kedua digunakan sebagai data uji. Data yang telah dikumpulkan yaitu, data nilai tukar Indonesian Rupiah ke Indonesian Rupiah, data nilai tukar Indonesian Rupiah ke Hongkong Dollar, data nilai tukar Indonesian Rupiah ke Japaneseese Yen.

4. Penentuan Data Input

Setelah pengumpulan data transaksi dilakukan, tahap selanjutnya yaitu menentukan data input yang digunakan sebagai data latih. Data latih diambil dari data transaksi 4 tahun terakhir dari sumber data. Data latih yang digunakan pada penelitian ini yaitu data kurs mata uang dari Nilai Tukar Indonesian Rupiah ke Indonesian Rupiah, Nilai Tukar Indonesian Rupiah ke Hongkong Dollar, dan Nilai Tukar Indonesian Rupiah ke Japanese Yen. Data latih ini digunakan sebagai data untuk perhitungan pada analisis metode Quantum Neural Network.

5. Proses Algoritma Quantum Neural Network

Tahap selanjutnya setelah data latih ditentukan yaitu, proses perhitungan pada metode Quantum Neural Network. Proses perhitungan ini dilakukan dengan menggunakan data latih yang telah di tentukan sebelumnya. Data latih yang telah disiapkan diinputkan ke dalam algoritma Quantum Neural Network untuk menentukan apakah data tersebut sesuai dengan parameter metode prediksi yang

p-ISSN:1693 - 2951; e-ISSN: 2503-2372 
akan digunakan. Pengujian ini dilakukan secara berulang untuk membuat algoritma Quantum Neural Network ini berlatih dan siap untuk dilakukan pengujian dengan data uji. Jika hasil uji coba ini berhasil maka dilakukan penggujian dengan menggunakan data uji yang disiapkan selanjutnya.

6. Penyusunan Data Set Pengujian

Penyusunan data uji dilakukan dengan mengumpulkan data uji lengkap yang berisikan parameter dan expected result. Data uji yang digunakan yaitu data kurs mata uang dari nilai tukar Indonesian Rupiah ke Indonesian Rupiah, nilai tukar Indonesian Rupiah ke Hongkong Dollar, dan nilai tukar Indonesian Rupiah ke Japaneseese Yen. Setelah itu data uji dimasukkan ke dalam fungsi sesuai dengan algoritma yang digunakan. Kemudian hasil perhitungan fungsi dibandingkan dengan expected result sebelum didapatkan persentase keakuratan hasil fungsi dengan expected result dari data uji.

7. Uji Coba Hasil Perhitungan Prediksi

Uji coba dilakukan dengan menginputkan data testing ke dalam algoritma yang telah dilakukan training secara berulang. Algoritma yang telah di lakukan training secara berulang akan menghasilkan hasil prediksi. Uji coba ini dilakukan untuk memastikan bahwa algoritma yang telah di proses menghasilkan hasil prediksi yang akan mendekati data aslinya.

8. Hasil Akhir Prediksi yang telah Diuji

Tahap akhir dari penelitian ini yaitu hasil akhir yang didapatkan setelah melakukan analisis dan uji coba pada metode yang diterapkan untuk memprediksi mata uang Rupiah ke dalam mata uang negara Asia. Hasil akhir prediksi ini di dapatkan setelah dilakukan uji coba dengan menggunakan data uji, sehingga dari hasil akhir ini dapat ditarik kesimpulan untuk dapat menjawab masalah yang telah diidentifikasi sebelumnya. Setelah dilakukan uji coba, hasil prediksi aka diukur dengan menggunakan Mean Absolute Precentage Error (MAPE) untuk mengukur akurasi sistem berdasarkan error yang dihasilkan.

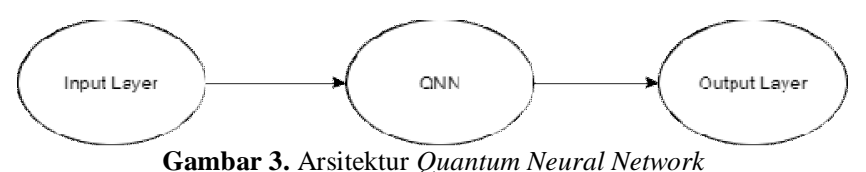

Gambar 3 merupakan arsitektur dari Quantum Neural Network. Proses yang terdapat pada arsitektur tersebut yaitu, input layer, QNN layer, dan output layer. Input layer merupakan lapisan pertama pada proses prediksi. Pada lapisan ini, nilai input dalam rentang $[0,1, \ldots .$.$] diubah menjadi status$ kuantum dengan nilai fase dalam rentang $[0, \pi / 2, \ldots .$. . Data yang telah diinput pada input layer selanjutnya diproses pada QNN layer. Setelah itu, hasil dari proses yang terjadi pada QNN layer akan diteruskan ke output layer.

\section{PEMBAHASAN}

Penelitian ini menggunakan data dari Data yang digunakan pada penelitian ini terdiri dari data training dan data testing. Data yang telah dikumpulkan yaitu data 20 tahun terakhir dari tahun 2000 hingga tahun 2020. Rincian data yang telah dikumpulkan yaitu :
1. Data nilai tukar Indonesian Rupiah ke Indonesian Rupiah

2. Data nilai tukar Indonesian Rupiah ke Hongkong Dollar

3. Data nilai tukar Indonesian Rupiah ke Japaneseese Yen.

Data yang telah dikumpulkan dibagi menjadi 2 bagian, yaitu data training dan data testing. Data training menggunakan $66 \%$ dari keseluruhan data. Sedangkan, data testing menggunakan keseluruhan data. Hal ini dilakukan untuk mengetahui kesesuaian data yang telah dilatih menggunakan data training dengan data hasil prediksi yang menggunakan data testing.

Data training dan data testing dikelompokkan berdasarkan banyaknya data dan keunikan dari seluruh data yang ada. Sehingga penentuan data training dan data testing ditentukan berdasarkan variable yg ada. Semakin banyak data training yang digunakan maka semakin akurat hasil prediksi yang dihasilkan.

TABEL 1

TABEL DATA TRAINING

\begin{tabular}{|c|c|c|c|}
\hline Tanggal & SGD & \multicolumn{1}{c|}{ JPY } & HKD \\
\hline $01 / 01 / 2000$ & 4738,3628 & 68,2891 & 904,9285 \\
\hline $02 / 01 / 2000$ & 4620,8872 & 68,2891 & 904,9285 \\
\hline $03 / 01 / 2000$ & 4710,886 & 67,9186 & 905,5217 \\
\hline $04 / 01 / 2000$ & 4672,518 & 67,7331 & 916,4861 \\
\hline $05 / 01 / 2000$ & 4661,5849 & 67,947 & 919,2296 \\
\hline $06 / 01 / 2000$ & 4664,7664 & 67,0528 & 908,0739 \\
\hline $07 / 01 / 2000$ & 4708,5875 & 68,2888 & 931,5855 \\
\hline $08 / 01 / 2000$ & 5051,9031 & 68,084 & 925,5354 \\
\hline $09 / 01 / 2000$ & 5044,4207 & 67,6978 & 922,8922 \\
\hline $10 / 01 / 2000$ & 4920,6509 & 67,8547 & 922,383 \\
\hline $11 / 01 / 2000$ & 4970,7425 & 68,9503 & 929,6221 \\
\hline $12 / 01 / 2000$ & 5007,0671 & 68,7901 & 932,4132 \\
\hline $13 / 01 / 2000$ & 4953,5879 & 68,8253 & 933,3555 \\
\hline $14 / 01 / 2000$ & 5094,3045 & 68,2537 & 924,9706 \\
\hline $15 / 01 / 2000$ & 5189,7674 & 68,9742 & 929,9237 \\
\hline $16 / 01 / 2000$ & 5458,1409 & 68,3838 & 924,4593 \\
\hline $17 / 01 / 2000$ & 5351,4653 & 69,082 & 939,8098 \\
\hline $18 / 01 / 2000$ & 5345,1753 & 70,2956 & 956,5209 \\
\hline $19 / 01 / 2000$ & 5337,1445 & 70,5677 & 952,147 \\
\hline $20 / 01 / 2000$ & 5206,2732 & 69,2108 & 953,2118 \\
\hline
\end{tabular}

Data Training pada penelitian ini merupakan data yang digunakan untuk melatih algoritma yang telah disusun sehingga Algoritma Quantum Neural Network dapat mengetahui pola peramalan. Data Training yang digunakan pada penelitian ini didapatkan dari proses pengumpulan data yang telah dilakukan sebelumnya. Data Training yang digunakan sebesar 66\% dari keseluruhan data. Data Training yang digunakan pada penelitian ini dapat dilihat pada Tabel 1. 
Data testing pada penelitian ini merupakan data yang digunakan untuk uji coba algoritma Quantum Neural Network. Uji coba ini digunakan untuk mengetahui kinerja algoritma yang telah dilatih sebelumnya. Kinerja dari algoritma ini diukur saat algoritma ini menemukan data yang baru dan belum pernah dilatih sebelumnya. Data testing yang digunakan pada penelitian ini dapat dilihat pada Tabel 2.

TABEL 2

TABEL DATA TESTING

\begin{tabular}{|c|r|r|r|}
\hline Tanggal & \multicolumn{1}{|c|}{ SGD } & \multicolumn{1}{c|}{ JYP } & \multicolumn{1}{c|}{ HKD } \\
\hline $01 / 06 / 2020$ & 10303,1184 & 128,7085 & 1793,4034 \\
\hline $02 / 06 / 2020$ & 10300,3302 & 129,1474 & 1799,4061 \\
\hline $03 / 06 / 2020$ & 10300,3302 & 128,1345 & 1791,8439 \\
\hline $04 / 06 / 2020$ & 10284,2954 & 128,3907 & 1791,8439 \\
\hline $05 / 06 / 2020$ & 10362,9978 & 127,8095 & 1795,3423 \\
\hline $06 / 06 / 2020$ & 10293,4383 & 127,8095 & 1797,1333 \\
\hline $07 / 06 / 2020$ & 10377,134 & 127,6165 & 1798,5508 \\
\hline $08 / 06 / 2020$ & 10420,2085 & 127,7853 & 1795,3092 \\
\hline $09 / 06 / 2020$ & 10417,152 & 127,7928 & 1791,1166 \\
\hline $10 / 06 / 2020$ & 10417,152 & 128,1244 & 1791,5528 \\
\hline $11 / 06 / 2020$ & 10349,4517 & 127,6033 & 1791,5528 \\
\hline $12 / 06 / 2020$ & 10311,621 & 127,61 & 1796,1183 \\
\hline $13 / 06 / 2020$ & 10357,6751 & 127,61 & 1795,5103 \\
\hline $14 / 06 / 2020$ & 10381,6967 & 127,8351 & 1788,1256 \\
\hline $15 / 06 / 2020$ & 10382,6644 & 127,8549 & 1793,3607 \\
\hline $16 / 06 / 2020$ & 10328,7355 & 126,9449 & 1793,3572 \\
\hline $17 / 06 / 2020$ & 10328,7355 & 127,3605 & 1792,061 \\
\hline $18 / 06 / 2020$ & 10421,6655 & 127,5621 & 1792,061 \\
\hline $19 / 06 / 2020$ & 10463,7879 & 127,8619 & 1787,4711 \\
\hline $20 / 06 / 2020$ & 10492,557 & 127,4665 & 1778,1829 \\
\hline & & & \\
\hline
\end{tabular}

Sistem yang dibuat pada penelitian ini yaitu, sebuah sistem sederhana yang dapat memprediksi mata uang dari beberapa negara Asia, diantaranya yaitu, Singapura, Jepang dan Hongkong. Sistem tersebut terdiri input data dan hasil prediksi. Pembuatan sistem pada penelitian ini menggunakan Bahasa Pemrograman Pyton dan aplikasi Open Source Juypiter Notebook.

Pembuatan sistem pada penelitian ini dilakukan melalui empat tahap, yaitu proses input data, proses mapping data, dan terakhir dilakukan Data Processing yang menghasilkan hasil dari prediksi.

\section{Input Data}

Data yang digunakan pada penelitian ini adalah data transaksi nilai tukar yang didapatkan pada transaksi valuta Putu Risanti Iswardani : Peramalan Nilai Tukar Rupiah... asing di salah satu instansi keuangan. Data tersebut terdiri dari 4 kolom, yaitu tanggal, nilai tukar Singaporean Dollar, nilai tukar Japaneseese Yen, dan nilai tukar Hongkong Dollar. Input data digunakan untuk menginputkan data yang telah dikumpulkan sebelumnya ke dalam sistem, sehingga nantinya akan digunakan sebagai bahan untuk pengolahan data pada Quantum Neural Network. Data yang telah diinputkan pada sistem akan dibagi menjadi dua yaitu, Data training yang digunakan untuk melatih Neural Network dan Data Testing untuk menguji Neural Network sehingga Neural Network dapat bekerja dengan maksimal. Seperti yang terlihat pada Gambar 4.

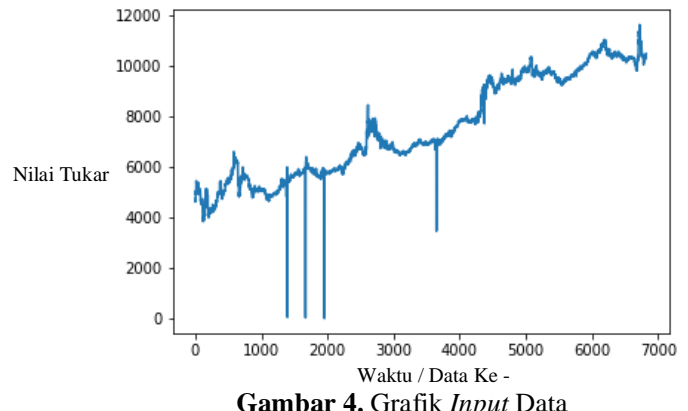

2. Data Processing

Data Processing pada penelitian ini terdiri dari input layer, LSTM, linear (Pendekatan Quantum), output layer. Input layer dilakukan untuk mengumpulkan data input nilai tukar. Input layer pada penelitian ini menggunakan 1 node input layer. Penelitian ini hanya menggunakan 1 node input layer dikarenakan data yang tersedia hanya data nilai tukar mata uang.

Tahap setelah dilakukan input layer yaitu tahap normalisasi. Tahap normalisasi dilakukan bertujuan agar Neural Network dapat membaca data yang akan di proses. Neural Network hanya dapat memproses data dari $0-1$. Sehingga sebelum dilakukan data processing maka dilakukan data normalisasi terlebih dahulu sehingga data input sebelumnya diubah menjadi rentan 0 hingga 1 , sepeti yang terlihat pada Tabel 3 .

TABEL 3

TABEL DATA TRAINING

\begin{tabular}{|c|c|c|}
\hline $\mathrm{x} 1$ & 4700 & 0 \\
\hline $\mathrm{x} 2$ & 4750 & 0.2 \\
\hline $\mathrm{x} 3$ & 4800 & 0.4 \\
\hline $\mathrm{x} 4$ & 4750 & 0.2 \\
\hline $\mathrm{x} 5$ & 4850 & 0.6 \\
\hline $\mathrm{x} 6$ & 4950 & 1 \\
\hline $\mathrm{x} 7$ & 4900 & 0.8 \\
\hline $\mathrm{x} 8$ & 4900 & 0.8 \\
\hline $\mathrm{x} 9$ & 4850 & 0.6 \\
\hline $\mathrm{x} 10$ & 4750 & 0.2 \\
\hline $\mathrm{xn}$ & $\ldots$ & $\ldots$ \\
\hline
\end{tabular}

p-ISSN:1693 - 2951; e-ISSN: 2503-2372

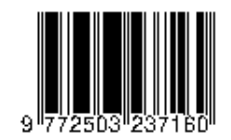


Proses normalisasi pada Quantum Neural Network dilakukan melalui beberapa tahapan. Berikut ini merupakan tahapan tahapan proses normalisasi.

a) Mengumpulkan data input nilai tukar

Data nilai tukar dikumpulkan terlebih dahulu agar lebih mudah untuk diurutkan pada proses normalisasi.

b) Mengurutkan data input dari nilai tukar terkecil ke terbesar Data input nilai tukar yang telah dikumpulkan diurutkan dari nilai yang terkecil hingga nilai yang terbesar. Hal ini bertujuan agar Neural Network lebih mudah membagi range 0 sampai dengan 1 .

c) Mencari jumlah data yang unik (Distinct)

Data yang telah diurutkan kemudian dikelompokkan berdasakan keunikannya. Jadi ketika data A memiliki 5 data, maka data unik yang diambil hanya 1 data $\mathrm{A}$.

d) Menghitung jumlah keunikan data dan membaginya diantara bilangan 0 sampai dengan 1

Data unik yang telah dicari kemudian dihitung dengan cara 1 : (jumlah data unik - 1)

e) Memberikan assign langkah ke input berdasarkan urutannya

Proses yang terjadi setelah input layer yaitu proses training. Proses training merupakan proses dimana Neural Network dilatih untuk bisa menebak perkiraan hasil prediksi. Gambar 5 merupakan proses training yang telah dilakukan oleh Quantum Neural Network. Proses training dilakukan dengan melakukan perulangan data dari 0 hingga $0-n$. Proses training dikatakan berhasil ketika loss yang dihasilkan semakin mendekati nilai 0 . Loss yang semakin mendekati 0 membuktikan bahwa Neural Network yang telah dilatih berhasil mempelajari pola dari prediksi nilai tukar.

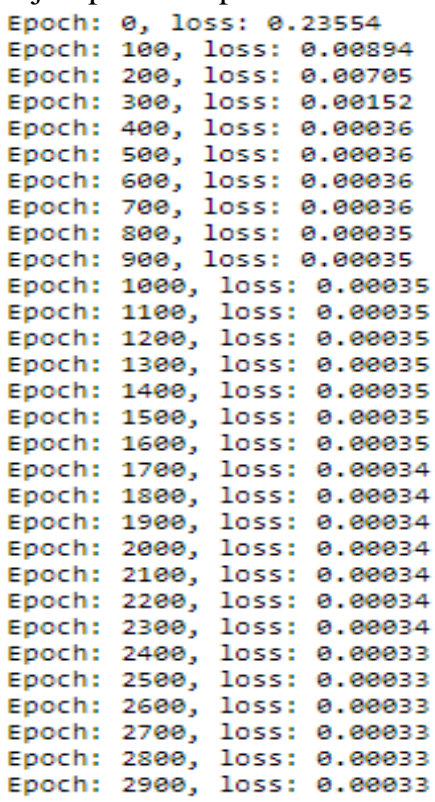

Gambar 5. Proses Training

\section{HASIl PEnElitian}

Peramalan nilai tukar rupiah ke mata uang Negara Asia telah melalui beberapa proses yang menghasilkan prediksi berupa angka yang menunjukkan nilai mata uang Negara Asia ketika dijadikan Rupiah. Hasil penelitian ini menghasilkan sebuah nilai yang merupakan hasil dari peramalan nilai tukar rupiah. Hasil penelitian ini didukung dengan adanya sebuah grafik yang dapat mengetahui seberapa dekat dan seberapa akurat data asli dengan data hasil prediksi yang dihasilkan. Grafik hasil prediksi dapat dilihat pada Gambar 6.

Data asli dan data hasil prediksi digambarkan dengan dua warna. Warna hijau merupakan data asli, sedangkan warna merah merupakan hasil dari sistem. Semakin warna merapat maka semakin akurat hasil yang di dapatkan oleh sistem.

Bagian kiri dari titik merah pada Gambar 6 merupakan hasil data training dan bagian kanan dari titik merah pada Gambar 6 menunjukkan hasil dari data uji. Dapat disimpulkan dari Gambar 6 menunjukkan bahwa hasil dari data uji sudah hampir mendekati dari data asli.
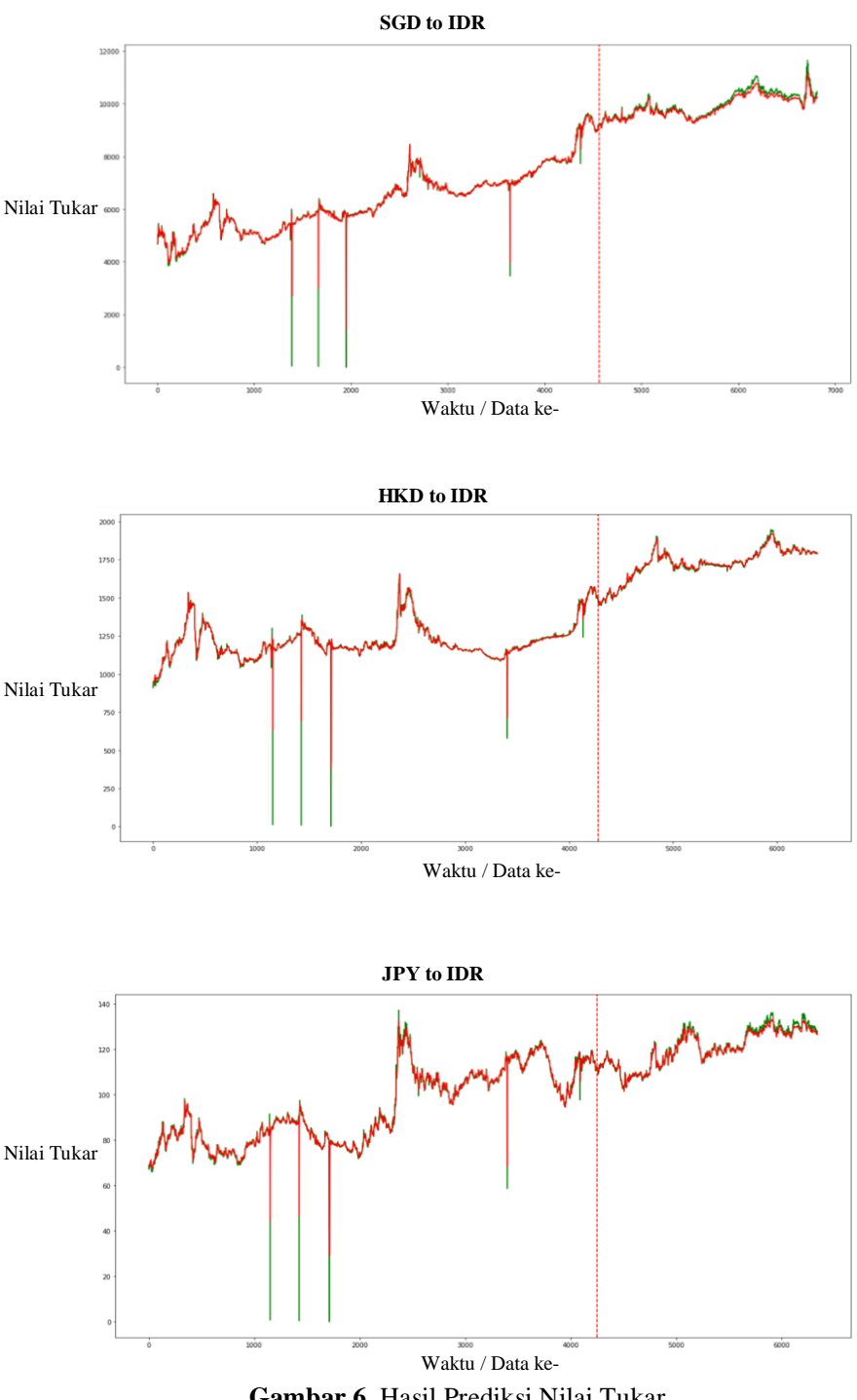

Hasil prediksi yang telah dilakukan menunjukkan bahwa hasil dari data uji sudah mendekati data asli. Terdapat beberapa data yang masih belum mendekati data aslinya. Ketidaksesuaian tersebut menunjukkan pola shifting, karena data prediksi selalu lebih tinggi atau lebih rendah dari data yang sebenarnya. Kendala lain yang ditemui, proses prediksi membutuhkan waktu sekitar 3 hingga 5 jam untuk sekali jalan. 1. Pengujian Sistem 
Data historis yang digunakan untuk pengujian berjumlah 6.820 buah, yang dimulai dari tanggal 4 Januari 1999 hingga tanggal 15 Juli 2020. Data yang digunakan untuk training adalah $66.6 \%$ dari keseluruhan data, yaitu sejumlah 4.542 data. Data yang digunakan untuk testing adalah $100 \%$ dari keseluruhan data. Dengan demikian, model Neural Network tidak mengetahui $33.3 \%$ (2.278 buah) dari data yang digunakan dalam testing.

Pengujian sistem pada penelitian ini dilakukan setelah hasil prediksi di dapatkan. Pengujian sistem pada penelitian ini digunakan untuk mengetahui tingkat akurasi dari hasil yang dihasilkan oleh sistem. Pengukuran tingkat akurasi pada penelitian ini menggunakan Mean Absolute Precentage Error (MAPE).

TABEL 4

TABEl PENGUJiAn SisteM


Tingkat akurasi dari prediksi nilai tukar yang bagus, yaitu ketika nilai yang dihasilkan dari MAPE minimal 10. Ketika hasil dari MAPE yang dihasilkan lebih dari 10 maka tingkat akurasi yang dihasilkan masih perlu di perbaiki lagi hingga mendapatkan nilai kurang dari 10.

Tabel 4 merupakan hasil pengukuran pengujian sistem berdasarkan nilai dari MAPE. Berdasarkan Tabel 4, rata rata dari nilai MAPE yang dihasilkan pada penelitian ini yaitu 0.22 pada Indonesian Rupiah ke Indonesian Rupiah, 0.43 pada Hongkong Dollar ke Indonesian Rupiah, dan 0.40 pada Japaneseese Yen ke Indonesian Rupiah. Sehingga tingkat akurasi prediksi nilai tukar dengan menggunakan Quantum Neural Network hampir mendekati data aslinya dengan ratarata nilai persentase error sebesar $0.22,0.43$, dan 0.40 . Jadi Hasil pengujian Quantum Neural Network dapat dikatakan akurat karena hasil pengukuran akurasi berdasarkan MAPE menunjukan bahwa akurasi yang dihasilkan sebesar $99.78 \%$ pada Indonesian Rupiah ke Indonesian Rupiah, 99.57\% pada Hongkong Dollar ke Indonesian Rupiah, dan 99.60\% pada Japaneseese Yen ke Indonesian Rupiah.

Putu Risanti Iswardani : Peramalan Nilai Tukar Rupiah...

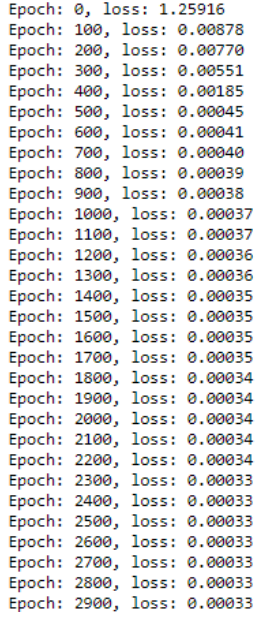

Gambar 7. Proses Training Singaporean Dollar ke Indonesian Rupiah

Pengujian pada setiap mata uang dilakukan pasca melatih model Neural Network sebanyak 2900 (dua ribu sembilan ratus) kali iterasi. Dapat dilihat pada Gambar 7 diatas, adalah log proses training untuk model Neural Network nilai tukar Singaporean Dollar ke Indonesian Rupiah. Berdasarkan log tersebut, dapat dilihat bahwa efisiensi model tertinggi mampu didapatkan pada iterasi ke 2900 dan seterusnya. Dengan demikian, dapat dilakukan optimasi di sisi training dengan mengurangi jumlah iterasi dari 2900 menjadi 2300.



Gambar 8. Proses Training Japaneseese Yen ke Indonesian Rupiah

Sama halnya dengan pengujian pada nilai tukar Japaneseese Yen ke Indonesian Rupiah. Dapat dilihat pada Gambar 8, bahwa iterasi paling efisien untuk masing-masing dataset ada di angka 2100. 
Epoch: 0 , loss: 0.08939 Epoch: 100, loss: 0.00330 Epoch: 200, loss: 0.00301 Epoch: 300, lo5s: 0.00244 Epoch: 400, loss: 0.00067 Epoch: 500, loss: 0.00054 Epoch: 600, loss: 0.00054 Epoch: 700, loss: 0.00054 Epoch: 800, loss: 0.00053 Epoch: 900, loss: 0.00053 Epoch: 1000, loss: 0.00052 Epoch: 1100, loss: 0.00052 Epoch: 1200 , loss: 0.00051 Epoch: 1300, loss: 0.00051 Epoch: 1400, loss: 0.00051 Epoch: 1500, loss: 0.00050 Epoch: 1600, loss: 0.00050 Epoch: 1700 , loss: 0.00050 Epoch: 1800, loss: 0.00049 Epoch: 1900, lo55: 0.00049 Epoch: 2000, loss: 0.00049 Epoch: 2100, loss: 0.00049 Epoch: 2200, loss: 0.00049 Epoch: 2300, los5: 0.00048 Epoch: 2400, los5: 0.00048 Epoch: 2500, loss: 0.00048 Epoch: 2600, loss: 0.00048 Epoch: 2700, lo5s: 0.00048 Epoch: 2800, lo5s: 0.00048 Epoch: 2900, loss: 0.00048

Gambar 9. Proses Training Hongkong Dollar ke Indonesian Rupiah

Sedangkan pengujian yang dilakukan pada nilai tukar Hongkong Dollar ke Indonesian Rupiah juga menunjukkan iterasi paling efisien untuk masing-masing dataset ada diangka 2400. Nilai iterasi untuk optimasi tersebut diatas sangat terikat pada algoritma dan dataset yang digunakan. Apabila algoritma Quantum Neural Network ini diubah, tentunya nilai iterasi paling efektif juga akan berubah. Semakin optimal algoritma yang digunakan, dan semakin banyak data time series yang disediakan untuk training, maka iterasi yang dibutuhkan akan lebih sedikit.

\section{KESIMPULAN}

Berdasarkan hasil penelitian yang telah dilakukan pada proses peramalan nilai tukar, dapat disimpulkan bahwa hasil peramalan nilai tukar telah mendekati data asli, sehingga peramalan nilai tukar dengan menggunakan pendekatan Quantum dapat dilakukan, walaupun proses yang dilakukan cukup lama. Pengujian yang telah diakukan pada penelitian ini mencakup dua bagian, yaitu pengujian $\log$ proses training dan pengujian akurasi dengan menggunakan Mean Absolute Precentage Error (MAPE).

Pengujian log training yang dilakukan pada nilai tukar Indonesian Rupiah ke Indonesian Rupiah menunjukkan iterasi yang paling efisien berada diangka 2300, Hongkong Dollar ke Indonesian Rupiah menunjukkan iterasi paling efisien berada diangka 2400 dan Japaneseese Yen ke Indonesian Rupiah menunjukkan iterasi paling efisien berada diangka 2400.

Berdasarkan pengujian akurasi dengan menggunakan MAPE didapatkan rata-rata nilai MAPE dari hasil prediksi sebesar 0.22 pada Indonesian Rupiah ke Indonesian Rupiah, 0.43 pada Hongkong Dollar ke Indonesian Rupiah, dan 0.40 pada Japanese Yen ke Indonesian Rupiah. Semakin mendekati 0 rata-rata nilai MAPE yang dihasilkan, semakin akurat hasil peramalan nilai tukar dengan menggunakan Quantum Neural Network. Sehingga, untuk akurasi dari algoritma ini dapat dikatakan akurat karena nilai akurasi sebesar $99.78 \%$ pada
Indonesian Rupiah ke Indonesian Rupiah, 99.57\% pada Hongkong Dollar ke Indonesian Rupiah, dan $99.60 \%$ pada Japanese Yen ke Indonesian Rupiah.

\section{REFERENSI}

[1] Kashifuddin Qazi, Igor Aizenberg, Towards Quantum Computing Algorithms for Datacenter Workload Predictions, IEEE International Conference. 2018

[2] Ida Ayu Masyuni, Peramalan Menggunakan Metode Holt-Winters Dioptimasi dengan Cat Swarm Optimization (Studi Kasus Pengujian Kendaraan Bermotor Kabupaten Tabanan), Tesis Magister Manajemen Sistem Informasi dan Komputer. 2018

[3] Primandani Arsi , Joko Prayogi. Optimasi Prediksi Nilai Tukar Rupiah Terhadap Dolar Menggunakan Neural Network Berbasiskan Algoritma Genetika. Jurnal Informatika. Vol 7 No 1. 2020

[4] Made Nita Dwi Sawitri, I Wayan Sumarjaya, Ni Ketut Tari Tastrawati, PERAMALAN MENGGUNAKAN METODE BACKPROPAGATION NEURAL NETWORK, E-journal Matematika. Vol 7 (3). 2018

[5] Aris Puji Widodo, Suhartono, Eko Adi Sarwoko, dan Zulfia Firdaus.Akurasi Model Prediksi Metode Backpropagation Menggunakan Kombinasi Hidden Neuron Dengan Alpha. Universitas Diponogoro. 2017

[6] Tao He, Tangren Dan, Yong Wei, Huazhong Li, Xu Chen, Guorong Qin. Particle Swarm Optimization RBF Neural Network Model for Internet Traffic Prediction. IEEE International Conference. 2016

[7] Suci Andriyani, Norenta Sitohang. Implementasi Metode Backpropagation Untuk Prediksi Harga Jual Kelapa Sawit Berdasarkan Kualitas Buah. Jurnal Teknologi dan Sistem Informasi. 2018

[8] Daneswara Jauhari, Imam Cholissodin, Candra Dewi. Prediksi Nilai Tukar Rupiah Indonesia Terhadap Dolar Amerika Serikat Menggunakan Metode Recurrent Extreme Learning Machine Neural Network. Jurnal Pengembangan Teknologi Informasi dan Ilmu Komputer. Vol 1, No.11. 2017

[9] Soheil Ganjefar, Morteza Tofighi. Optimization of quantum-inspired Neural Network using memetic algorithm for function approximation and chaotic time series prediction. Neurocomputing. 2018

[10] Lipantri Mashur Gultom. Klasifikasi Data Dengan Quantum Perceptron. Jurnal Teknovasi Medan. 2017

[11] Safira Yasmin Amalutfia, Moh Hafiyusholeh. Analisis Peramalan Nilai Tukar Rupiah terhadap Dollar dan Yen menggunakan FTS-MARKOV CHAIN. Jurnal Pendidikan Unisla. 2020

[12] Gilang Bimasakti Andhika1, I Wayan Sumarjaya2, I Gusti Ayu Made Srinadi. Peramalan Nilai Tukar Petani Menggunakan Metode Singular Spectrum Analysis. E-journal Matematika Universitas Udayana. 2020

[13] G.P. Brian Are, Sampe Hotlan Sitorus. Prediksi Nilai Tukar Mata Uang Rupiah Terhadap Dolar Amerika Menggunakan Metode Hidden Markov Model. Jurnal Komputer dan Aplikasi. 2020

[14] Ari Pani Desvina, Inggrid Octaviani Meijer. Penerapan Model ARCH/GARCH untuk Peramalan Nilai Tukar Petani. Jurnal Sains Matematika dan statistika, vol 4 No 1.2018

[15] Nina Valentika. Peramalan Kurs, Inflasi, Impor Dan Ekspor Dengan Vecm. Journal Accounting Information System. 2020

[16] Kerstin Beer, Dmytro Bondarenko, Terry Farrelly. Training deep Quantum Neural Networks. Nature Communication. 2020

[17] Amira Abbas, David Sutter, Christa Zoufal. The power of Quantum Neural Networks. airXiv. 2020

[18] S. K. Jeswal1, S. Chakraverty. Recent Developments and Applications in Quantum Neural Network. ResearchGate. 2018

[19] L. G. Wright and P. L. McMahon, "The Capacity of Quantum Neural Networks," in Conference on Lasers and Electro-Optics, OSA Technical Digest (Optical Society of America, 2020), paper JM4G.5.2020

[20] Zhih - Ahn Jia, Biao Yi, Rui Zhai. Quantum Neural Network States: A Brief Review of Methods and Applications. Advanced Quantum Technologies, Vol 2, Issue7-8. 2019

[21] Hou Xuan. Research on Quantum Adaptive Resonance Theory Neural Network. International Conference on Electronic \& mechanical Engineering and Information Technology.2011 